Perception of Risk From Radiation

\author{
Paul Slovic \\ Decision Research \\ 1201 Oak Street \\ Eugene, Oregon 97401
}

(541) $485-2400$

fax (541) 485-2403

email:PSLOVIC@OREGON.UOREGON.EDU

January 2, 1996 
Perception of Risk From Radiation / 2

\title{
PERCEPTION OF RISK FROM RADIATION
}

\author{
Paul Slovic
}

How does the public perceive the risks associated with exposure to radiation? Perhaps the most important generalization from research in this domain is that there is no uniform or consistent perception of radiation risks. This is what makes this topic so fascinating to study. Public perception and acceptance is determined by the context in which radiation is used-and the very different reactions to different uses provide insight into the nature of perception and the determinants of acceptable risk.

A second generalization, and a disturbing one, is that in every context of use, with the exception of nuclear weapons, public perceptions of radiation risk differ from the assessments of the majority of experts on radiation and its effects. In some cases, members of the public see far greater risks associated with a radiation technology than do technical experts-in others the public is much less concerned than the experts believe they should be. Although differences between perceptions of laypersons and those of experts cannot be attributed in any simple way to degree of knowledge, it is clear that better information and education about radiation and its consequences is needed. With the exception of studies that have designed brochures to help people understand their risk from radon, there has been little effort or progress made on the communication side.

There is a particularly urgent need to develop plans and materials for communicating with the public in the event of a radiological disaster. This point is driven home by the difficulties observed in Europe after Chernobyl, and in the chaos and disruption that reigned in Goiania, 
Perception of Risk From Radiation / 3

Brazil, after two scavengers unwittingly sawed open a capsule containing cesium that had been used for cancer therapy.

During the remainder of this paper I shall attempt to elaborate these points by highlighting some key results and conclusions pertaining to

- the nature of risk perceptions,

- the impacts of perceptions, and

- the need for communication about radiological hazards.

\section{The Psychometric Paradigm}

One broad strategy for studying perceived risk is to develop a taxonomy for hazards that can be used to understand and predict responses to their risks. A taxonomic scheme might explain, for example, people's extreme aversion to some hazards, their indifference to others, and the discrepancies between these reactions and experts' opinions. One approach to this goal has employed the psychometric paradigm ${ }^{(1)}$ which uses psychophysical scaling and multivariate analysis techniques to produce quantitative representations or "cognitive maps" of risk attitudes and perceptions.

Within the psychometric paradigm, people make quantitative judgments about the current and desired riskiness of diverse hazards and the desired level of regulation of each. In one of the earliest psychometric studies, four different groups of people were asked to rate 30 activities (e.g., smoking, fire fighting), substances (e.g., food coloring), and technologies (e.g., railroads, aviation) according to the present risk of death from each. ${ }^{(2-3)}$ Three groups were from Eugene, Oregon; they included 30 college students, 40 members of the League of Women Voters (LOWV), and 25 business and professional members of the "Active Club." The fourth group was 
Perception of Risk From Radiation / 4 composed of 15 persons selected nationwide for their professional involvement in risk assessment. This "expert" group included a geographer, an environmental policy analyst, an economist, a lawyer, a biologist, a biochemist, and a government regulator of hazardous materials.

Each were asked, for each of the 30 items, "to consider the risk of dying (across all U.S. society as a whole) as a consequence of this activity or technology." To make the evaluation task easier, each activity appeared on a 3" $\times 5^{\prime \prime}$ card. Respondents were told first to study the items individually, thinking of all the possible ways someone might die from each (e.g., fatalities from non-nuclear electricity were to include deaths resulting from the mining of coal and other energy production activities as well as electrocution; motor vehicle fatalities were to include collisions with bicycles and pedestrians). Next, the were to order the items from least to most risky and, finally, to assign numerical risk values by giving a rating of 10 to the least risky item and making the other ratings accordingly. They were also given additional suggestions, clarifications, and encouragement to do as accurate a job as possible.

Table 1 shows how the various groups ranked these 30 activities and technologies according to riskiness. There were many similarities between the three groups of laypeople. For example, each group believed that motorcycles, motor vehicles, and handguns were highly risky, while vaccinations, home appliances, power mowers, and football posed relatively little risk. However, there were strong differences as well. Active Club members viewed pesticides and spray cans as relatively much safer than did the other groups. Nuclear power was rated as highest in risk by the LOWV and student groups, but only eighth by the Active Club. The students viewed contraceptives as riskier and mountain climbing as safer than did the other lay groups. Experts' 
Perception of Risk From Radiation / 5

judgments of risk differed markedly from the judgments of laypeople. The experts viewed electric power, surgery, swimming, and X-rays as more risky than did the other groups, and they judged nuclear power, police work, and mountain climbing to be much less risky.

Insert Table 1 about here

In an attempt to understand why some hazards were rated more risky than others, Fischhoff, Slovic, Lichtenstein, Read, and Combs ${ }^{(2)}$ borrowed a technique from personality theorists and tried to assess what might be called the "personality" of hazards. They asked people, in addition to estimating the perception of risk, to evaluate each hazard item or activity on a variety of scales that were hypothesized to be related to the perception and acceptance of risk-such as whether exposure to the activity is voluntary or not, whether it has the potential to be catastrophic, whether it evokes an emotional reaction, whether it can kill people or not, how well known it is to those exposed or to science, whether its effects are immediate vs. delayed, whether it is controllable or noncontrollable, whether the technology involved is new vs. old, and whether the risk situation is equitable vs. not equitable. (Equity is a concept whereby people who bear the risk also get the benefit. If a risk situation is not equitable, then one person gets the benefit, and someone else gets the risk.) From these ratings, profiles emerged (see Figure 1) much like personality profiles. They found that, not only do nuclear power and X-rays, for example, have a very different stature on perception of risk, they also have very different profiles. The quality of their risks was judged to be different. Nuclear power was seen as less voluntary, more catastrophic, higher in dread, more likely to be fatal, less controllable, newer, and so forth. They also found that these qualities were not independent across hazards. They tended to be associated 
Perception of Risk From Radiation / 6

across the domain of hazards. If something was judged to be voluntary, it tended also to be seen as controllable. If something was judged to be catastrophic, it also tended to be judged as fatal, and so forth.

Insert Figure 1 about here

Fischhoff et al. ${ }^{(2)}$ performed a factor analysis on the relationships among these variables, which yielded two very strong factors that we called "dread" risk and "unknown" risk. The "dread" risk factor was combined from three scales which loaded on that factor-dread, catastrophic potential, and fatal. The "unknown" risk factor combined judgments on the scales unknown, unfamiliar, and delayed consequences.

Slovic, Fischhoff, and Lichtenstein ${ }^{(4)}$ conducted a new study with a much larger number of scales, and a larger number of items, some 90 hazards rated on 15 scales. Again, factor analysis yielded a two-factor representation, with the factors designated as "dread" and "unknown." However, in this case, the dread factor loaded on uncontrollable, catastrophic, fatal, not equitable, high risk to future generations, not easily reduced, and involuntary. The "unknown" factor loaded on unobservable, delayed effects, and so forth. The space, shown in Figure 2, was very revealing. Nuclear energy hazards and chemical hazards were located in the unknown and dread quadrant of the space. Medicines tended to fall in the upper left quadrant, everyday hazards in the lower left quadrant, and common catastrophic hazards in the lower right quadrant.

Insert Figure 2 about here 
Perception of Risk From Radiation / 7

Additional research has shown that laypeople's risk perceptions and attitudes are closely related to the position of a hazard within the factor space shown in Figure 2. Most important is the factor Dread Risk. The higher a hazard's score on this factor (i.e., the further to the right it appears in the space), the higher its perceived risk, the more people want to see its current risks reduced, and the more they want to see strict regulation employed to achieve the desired reduction in risk. In contrast, experts' perceptions of risk are not closely related to any of the various risk characteristics or factors derived from these characteristics. Instead, as noted earlier, experts appear to see riskiness as synonymous with expected annual mortality. As a result, some conflicts over "risk" may result from experts and laypeople having different definitions of the concept.

\section{Perception of Radiation Risk}

Numerous psychometric surveys conducted during the past decade have examined perceptions of risk and benefit from various radiation technologies. This work shows that there is no general pattern of perception for radiation. Different sources of radiation exposure are perceived in different ways. This was evident in the first psychometric study, summarized in Table 1. There we see that three groups of laypersons perceived nuclear power as having very high risk (rank 1, 1, and 8 out of 30 hazards) whereas a group of risk-assessment experts had a mean risk rating that put nuclear power 20 th in the hierarchy. Note also that the three groups of laypersons judged medical X-rays relatively low in risk (ranks 22, 17, and 24), whereas the experts placed it 7 th. Thus we see that two radiation technologies were perceived differently from one another and differently from the views of experts. 
Figure 2 further illustrates the differences in perception of various radiation hazards. Note that nuclear-reactor accidents, radioactive waste, and fallout from nuclear weapons testing are located in the upper-right quadrant of the factor space, reflecting people's perceptions that these technologies are uncontrollable, dread, catastrophic, lethal, and inequitable in their distribution of risks and benefits. Diagnostic X-rays are perceived much more favorably on these scales, hence they fall in the upper-left quadrant of the space. Nuclear weapons fall in the lower-right quadrant, separating from nuclear-reactor accidents, nuclear waste, and fallout on the scales measuring knowledge, immediacy of effects, and observability of effects.

Although Table 1 and Figure 2 represent data from small and nonrepresentative samples collected a decade or more ago, recent surveys of the general public in the U.S., Sweden, and Canada show consistently that nuclear power and nuclear waste are perceived as extremely high in risk and low in benefit to society, whereas medical $\mathrm{X}$-rays are perceived as very beneficial and low in risk. ${ }^{(5-7)}$ Smaller studies in Norway and Hungary have also obtained these results. ${ }^{(8-9)}$

Perceptions of risk associated with nuclear waste are even more negative than perceptions of nuclear power. ${ }^{(5,10-14)}$ When asked to state whatever images or associations came to mind when they heard the words "underground nuclear waste storage facility," a representative sample of Phoenix, Arizona, residents could hardly think of anything that was not frightening or problematic (see Table 2). The disposal of nuclear wastes is a technology that experts believe can be managed safely and effectively. The discrepancy between this view and the images shown in Table 2 is indeed startling. 
Perception of Risk From Radiation / 9

The perception of nuclear power as a catastrophic technology was studied in depth by Slovic, Lichtenstein, and Fischhoff. ${ }^{(15)}$ They found that, before the TMI accident, people expected nuclear-power accidents to lead to disasters of immense proportions. Scenarios of reactor accidents were found to resemble scenarios of the aftermath of nuclear war. Replication of these studies after the TMI event found even more extreme "images of disaster."

The powerful negative imagery evoked by nuclear power and radiation is discussed from a historical perspective by Weart. ${ }^{(16)}$ Weart argues that modern thinking about radioactivity employs beliefs and symbols that have been associated for centuries with the concept of transmutation - the passage through destruction to rebirth. In the early decades of the 20 th century, transmutation images became centered on radioactivity, which was associated with "uncanny rays that brought hideous death or miraculous new life; with mad scientists and their ambiguous monsters; with cosmic secrets of life and death; ...and with weapons great enough to destroy the world..." (p. 42).

But this concept of transmutation has a duality that is hardly evident in the imagery associated with nuclear power and nuclear wastes. Why has the evil overwhelmed the good? The answer undoubtedly involves the bombing of Hiroshima and Nagasaki, which linked the dread images to reality. The sprouting of nuclear power in the aftermath of the atomic bombing has led Smith ${ }^{(17)}$ to observe:

Nuclear energy was conceived in secrecy, born in war, and first revealed to the world in horror. No matter how much proponents try to separate the peaceful from the weapons atom, the connection is firmly embedded in the minds of the public. (p. 62) 
Additional insights into the special quality of nuclear fear are provided by Erikson, ${ }^{(18)}$ who draws attention to the broad, emerging theme of toxicity, both radioactive and chemical, that characterizes a "whole new species of trouble" associated with modern technological disasters. Erikson describes the exceptionally dread quality of technological accidents that expose people to radiation and chemicals in ways that "contaminate rather than merely damage; ...pollute, befoul, and taint rather than just create wreckage; ...penetrate human tissue indirectly rather than wound the surface by assaults of a more straightforward kind" (p. 120). Unlike natural disasters, these accidents are unbounded. Unlike conventional disaster plots, they have no end. "Invisible contaminants remain a part of the surroundings-absorbed into the grain of the landscape, the tissues of the body, and, worst of all, into the genetic material of the survivors. An 'all clear' is never sounded. The book of accounts is never closed" (p. 121).

Erikson's "contamination model" may explain, in part, the reaction of the public to exposures to carcinogens. Numerous studies have found that a high percentage (60-75\%) of people believe that if a person is exposed to a chemical that can cause cancer, that person will probably get cancer some day. ${ }^{(20-21)}$ A similarly high percentage believe that "exposure to radiation will probably lead to cancer some day."(21) The belief that any exposure to a carcinogen is likely to lead to cancer tends to coincide with the belief that it can never be too expensive to reduce such risks. ${ }^{(20)}$ Therefore, it is not surprising to find in an analysis of more than 500 life-saving interventions by Tengs et al. ${ }^{(2)}$ that radiation controls in industry were associated with the highest costs per year of life saved.

The deep fears and anxieties associated with radiation and with nuclear power make the cases in which radiation is responded to rather casually of particular interest. For example, Sandman, 
Perception of Risk From Radiation / 11

Weinstein, and Klotz ${ }^{(23)}$ surveyed residents in the Reading Prong area of New Jersey, a region characterized by very high radon levels in many homes. They found that residents there were basically apathetic about the risk. Few had bothered to monitor their homes for radon. Most believed that, although radon might be a problem for their neighbors, their own homes did not have any problem.

A striking contrast to the apathy regarding radon in homes is the strong public reaction that developed in many New Jersey cities when the state attempted to develop a landfill in which to place 14,000 barrels of mildly radioactive soil. The soil had been excavated from the former site of a radium watch-dial factory that had operated at the turn of the century. Over a period of several years, the state tried in vain to find a community that would accept the soil. ${ }^{(24)}$

Table 3 summarizes the status of perceived risk for six radiation technologies, contrasting the views of technical experts with the views of the general public. In addition to nuclear power, nuclear waste, X-rays, radon, and nuclear weapons, food irradiation ${ }^{(25)}$ and a source of nonionizing radiation, electric and magnetic fields (EMF), are included in the table, although there is relatively less information about perceptions of these two sources. We see that there is typically disagreement between the experts and the public regarding the level of risk and its acceptability. To my knowledge there have been only two published studies thus far of perceptions of risk from electric and magnetic fields. Both of these studies, by Morgan et al. ${ }^{(26)}$ and MacGregor, Slovic, and Morgan, ${ }^{(27)}$ found that perceived risks associated with fields from home appliances and electric blankets were relatively low; and that perceived risks associated with large power lines were relatively high. Both studies also showed that, when the respondents were given a briefing about research on health effects of electric fields (which said that many studies had been done 
but no adverse human health effects had yet been reliably demonstrated), their perceptions on subsequent retest shifted toward greater perceived risk. MacGregor et al. found that this briefing (in the form of a brochure) also lead to greater dread (particularly regarding power-line risks) less perceived equity, and greater concern regarding effects of EMF on the nervous system, the immune system, cell growth and reproduction, chronic depression, and cancer. These results imply that, as concerns (and reports of research) about the risks from electric and magnetic fields continue to be publicized, public fears will increase. The significance of the public's uneasiness about these fields is documented by Florig, ${ }^{(28)}$ who estimated that the utility industry spends more than one billion dollars annually attempting to mitigate public concerns.

\section{Insert Table 3 about here}

Conspicuously missing from Table 3 is exposure from radiation medicine. An extensive search of Medline and six other data bases using key words such as radiation, risk perception, fear, and nuclear medicine failed to uncover any studies of perception of risk regarding the use of radionuclides in medicine.

It is instructive to compare perceptions of risk and benefit for various radiation technologies with perceptions of various chemical technologies. Concerns about chemical risks have risen dramatically in the past decade, spurred by well-publicized crises at Love Canal, New York, Times Beach, Missouri, and many other waste sites; by major accidents at Seveso, Italy, Bhopal, India, and Prince William Sound, Alaska; and by numerous other problems such as the contamination of ground water and flour with the pesticide ethylene dibromide (EDB) and the controversy regarding the use of Alar, a growth regulator, in apples. The image of chemical 
Perception of Risk From Radiation / 13 technologies is so negative that when you ask members of the general public to tell you what first comes to mind when they hear the word "chemicals," by far the most frequent response is "dangerous" or some synonym (e.g., toxic, hazardous, poison, deadly). Chemicals in general and agricultural and industrial chemicals in particular are seen as very high risk and very low benefit, as are nuclear power and nuclear-waste technologies. However, just as medical uses of radiation (such as X-rays) are perceived in a very favorable way, differently from other radiation technologies, so are prescription drugs, which are a very potent and toxic category of chemicals to which we are often exposed at high doses. Figure 3 , taken from a study in Canada ${ }^{(7)}$ illustrates the parallels between nuclear power and nonmedical chemicals (pesticides) seen as high in risk and low in benefit and between X-rays and prescription drugs (high benefit/low to moderate risk). A national survey in Sweden has shown much the same results. ${ }^{(6)}$

Insert Figure 3 about here

Lessons

What does this research tell us about the acceptance of risk from radiation? There seem to be several lessons:

First, although many technical experts have labeled public reactions as irrational or phobic, such accusations are clearly unjustified. ${ }^{(29)}$ There is a logic to public perceptions and behaviors that has become apparent through research. For example, the acceptance afforded X-rays and prescription drugs suggests that acceptance of risk is conditioned by perceptions of direct benefits and by trust in the managers of the technology, in this case the medical and pharmaceutical professions. The managers of nuclear power and nonmedical chemical 
technologies are clearly less trusted and the benefits of these technologies are not highly appreciated, hence their risks are less acceptable. High risks from nuclear weapons are tolerated because of their perceived necessity (and probably also because people lack knowledge about how to intervene in military security issues; they do have such knowledge and opportunities to intervene in the management of nuclear power).

The apathetic response to the risk from radon appears to result from the fact that it is of natural origin, occurring in a comfortable, familiar setting, with no one to blame. Moreover, it can never be totally eliminated. Opposition to the burial of radioactive soil, on the other hand, likely derives from the fact that this hazard is imported, technological in origin, industry and the state are blameworthy, it is involuntary, has a visible focus (the barrels or the landfill), and can be totally eliminated by preventing the deposition in the landfill. ${ }^{(23)}$

\section{The Impacts of Perceptions}

It has become quite clear that, whether or not one agrees with public risk perceptions, they form a reality that cannot be ignored in risk management. The impact of public perceptions on regulatory agencies is illustrated by the report of a task force assembled by the Environmental Protection Agency to evaluate the Agency's priorities. ${ }^{(30)}$ The task force concluded that EPA's actual priorities and legislative authorities corresponded more closely with public opinion than they did with the task force's estimates of the relative risks.

\section{Ripple Effects}

During the past decade, research has also shown that individual risk perceptions and cognitions, interacting with social and institutional forces, can trigger massive social, political, and economic impacts. Early theories equated the magnitude of impact to the number of people 
killed or injured, or to the amount of property damaged. The accident at TMI, however, provided a dramatic demonstration that factors besides injury, death, and property damage impose serious costs. Despite the fact that not a single person died at TMI, and few if any latent cancer fatalities were expected, no other accident in our history has produced such costly societal impacts. ${ }^{(31-32)}$ In addition to its impact on the utility that owned and operated the plant, this accident also imposed enormous costs on the nuclear industry and on society. These came from stricter regulation, reduced operation of reactors worldwide, greater public opposition to nuclear power, reliance on more expensive energy sources, and increased costs of reactor construction and operation.

A theory aimed at describing how psychological, social, cultural, and political factors interact to "amplify risk" and produce ripple effects has been presented by Kasperson et al. ${ }^{(33)}$ An important element of this theory is the assumption that the perceived seriousness of an accident or other unfortunate event, the media coverage it gets, and the long-range costs and other higherorder impacts on the responsible company, industry, or agency are determined, in part, by what the event signals or portends. Signal value reflects the perception that the event provides new information about the likelihood of similar or more destructive future mishaps.

The informativeness or signal value of an event, and thus its potential social impact, appears to be systematically related to the characteristics of the hazard. An accident that takes many lives may produce relatively little social disturbance (beyond that caused the victims' families and friends) if it occurs as part of a familiar and well-understood system (e.g., a train wreck). However, a small accident in an unfamiliar system (or one perceived as poorly understood), such 
Perception of Risk From Radiation / 16

as a nuclear reactor, may have immense social consequences if it is perceived as a harbinger of further (and possible catastrophic) mishaps.

The concept of accidents as signals helps explain our society's strong response to problems involving nuclear power and nuclear wastes. Because these nuclear hazards are seen as poorly understood and catastrophic, accidents anywhere may be seen as omens of future disasters everywhere, thus producing large socioeconomic and political impacts.

\section{$\underline{\text { Stigma }}$}

Substantial socioeconomic impacts may also result from the stigma associated with radiation contamination. The word stigma was used by the ancient Greeks to refer to bodily marks or brands that were designed to expose infamy or disgrace - to show, for example, that the bearer was a slave or criminal. As used today, the word denotes someone "marked" as deviant, flawed, spoiled, or generally undesirable in the view of some observer. When the stigmatizing characteristic is observed, the person is denigrated or avoided. Prime targets for stigmatization are members of minority groups, the aged, homosexuals, drug addicts, alcoholics, and persons afflicted with physical or mental disabilities and deformities.

A dramatic example of stigmatization involving radiation occurred in September, 1987, in Goiania, Brazil, where two men searching for scrap metal dismantled a cancer therapy device in an abandoned clinic. In doing so, they sawed open a capsule containing 28 grams of cesium chloride. Children and workers nearby were attracted to the glowing material and began playing with it. Before the danger was realized, several hundred people became contaminated and four persons eventually died from acute radiation poisoning. Publicity about the incident led to stigmatization of the region and its residents. ${ }^{(34)}$ Hotels in other parts of the country refused to 
allow Goiania residents to register, airline pilots refused to fly with Goiania residents on board, automobiles driven by Goianians were stoned, hotel occupancy in the region dropped $60 \%$ for six weeks following the incident, and virtually all conventions were canceled during this period. The sale prices of products manufactured in Goiania dropped by $40 \%$ after the first news reports and remained depressed for a period of 30-45 days despite the fact that no items were ever found to have been contaminated.

\section{Risk Communication: Placing Radiation Risks in Perspective}

Given the importance of risk perceptions and the extraordinary divergence between perceptions of experts" and laypersons in the domains of chemical and radiation technologies, it is not surprising that there has been a burgeoning interest in the topic of "risk communication." Much has been written about the need to inform and educate people about risk and the difficulties of doing so. ${ }^{(35-43)}$ As many writers have observed, doing an adequate job of communicating about r̆isk means finding comprehensible ways of presenting complex technical material that is clouded by uncertainty and is inherently difficult to understand.

The crux of the cornmunication problem is providing information that puts risk into perspective in a way that facilitates decision making. One important lesson emerged from the 1983-1984 controversy over ethylene dibromide, a widely used pesticide that was detected at very low levels in packaged foods. The Environmental Protection Agency, which was responsible for regulating ethylene dibromide, disseminated information about the aggregate risk of this chemical to the exposed population. Although the media accurately transmitted EPA's "macro" analysis, newspaper editorials and public reaction clearly indicated an inability to translate this into a "micro" perspective on the risk to an exposed individual. What the newspaper 
Perception of Risk From Radiation / 18

reader or TV viewer wanted to know, and had trouble learning, was the answer to the question

"Should I eat the bread?"(44)

\section{$\underline{\text { Risk Comparisons }}$}

One of the few "principles" in this field that seems to be useful is the assertion that comparisons are more meaningful than absolute numbers or probabilities, especially when these absolute values are quite small. Sowby $(45)$ argued that to decide whether or not we are responding adequately" to radiation risks we need to compare them to "some of the other risks of life." Rothschild ${ }^{(46)}$ observed "There is no point in getting into a panic about the risks of life until you have compared the risks which worry you with those that don't, but perhaps should."

Typically, such exhortations are followed by elaborate tables and even "catalogs of risks" in which diverse indices of death or disability are displayed for a broad spectrum of life's hazards. Thus Sowby ${ }^{(45)}$ provided extensive data on risks per hour of exposure, showing, for example, that an hour riding a motorcycle is as risky as an hour of being 75 years old. Wilson ${ }^{(47)}$ developed a table of activities (e.g., flying 1000 miles by jet, having one chest X-ray), each of which is estimated to increase one's annual chance of death by 1 in one million. Cohen and Lee ${ }^{(48)}$ rank ordered milany hazards in terms of their reduction in life expectancy on the assumption that "to some approximation, the ordering should be society's order of priorities. However, we see several very major problems that have received very little attention ... whereas some of the items near the bottom of the list, especially those involving radiation, receive a great deal of attention" (p. 720). A related exercise by Reissland and Harries ${ }^{(49)}$ compared loss of life expectancy in the nuclear industry with that in other occupations. 
Although such risk comparisons may provide some aid to intuition, they do not educate as effectively as their proponents have assumed. For example, although some people may feel enlightened on learning that a single takeoff or landing in a commercial airliner takes an average of 15 minutes off one's life expectancy, others may find themselves completely bewildered by such information. When landing or taking off, one will either die prematurely (almost certainly by more than 15 minutes) or one will not. From the standpoint of the individual, averages do not adequately capture the essence of such risks.

Furthermore, the research on risk perception described earlier shows that perception and acceptance of risk are determined not only by accident probabilities, annual mortality rates, and losses of life expectancy, but also by numerous other characteristics of hazards such as benefits, uncertainty, controllability, catastrophic potential, equity, and threat to future generations. Therefore, the fact that a particular risk is smaller, by comparison, than other risks that are considered acceptable, does not necessarily imply that it, too, should be acceptable. Moreover, within the perceptual space defined by the various characteristics of risks, each hazard is unique. A statement such as "the annual risk from living near a nuclear power plant is equivalent to the risk of riding an extra 3 miles in an automobile" fails to consider how these two technologies differ on the many qualities that people believe to be important. As a result, such statements are likely to produce anger rather than enlightenment and they are not likely to be convincing in the face of criticism. ${ }^{(50-51)}$

In sum, comparisons across diverse hazards may be useful tools for educating the public. Yet the facts do not speak for themselves. Comparative analyses must be performed with great care to be worthwhile. 
Fortunately, radiation risks can be compared in a number of useful and defensible ways. Radiation emissions can be measured and comparisons can be made between actual or potential exposure levels of concern and familiar, everyday exposures from natural sources of radiation or medical X-rays and treatments. By making comparisons from one source of radiation to another, one avoids the apples vs. oranges comparisons that befuddle and anger people.

Wilson ${ }^{(52)}$ used comparisons with natural sources of radiation to put the risks from the Chernobyl accident into perspective for the 2 million people living downwind from the reactor in Byelorussia. He noted that the estimated increased lifetime dose was 0.7 rem for each of these persons and that this is considerably less than the difference in the lifetime external dose a person receives on moving from New York to Denver. It is also less than the difference in the dose a person receives from inhaled radon if he or she moves from an average New England house to an average Pennsylvania house.

When radiation from Chernobyl reached the United States, the Inter-Agency Task Force, chaired by EPA administrator Lee Thomas, used similar comparisons to illustrate the low level of risk involved. Media stories pointed out that exposures in the U.S. were a small fraction of the exposure from a chest X-ray. A news story from Portland, Oregon indicated that readings of 2.9 picocuries of iodine-131 per cubic meter of air were insignificant compared to the 2700 picocurie level that would trigger concern.

This discussion is not meant to imply that we already know how to communicate radiation risks effectively. Communication about Chernobyl was dreadful in Europe. ${ }^{(53-57)}$ Information messages were peppered with different terms (roentgens, curies, bequerels, rads, rems, sieverts, grays) which were explained poorly or not at all. Public anxiety was high and not always related 
to actual threat. Public officials were at odds with one another and inconsistent in their evaluations of risks from consuming various kinds of food or milk. Comparisons with exposure to natural radiation from familiar activities were not well received because the media and the public did not trust the sources of such information. Other comparisons (e.g., with background cancer rates) fared even worse. Many of the statements made by officials to calm the public confused and angered them instead. Although communications in the U.S. effectively maintained a calm perspective, one could say that U.S. officials had a relatively easy job. All they had to do was convince people that minuscule levels of radiation were not a threat. Had there been higher levels and "hot spots" as in the Soviet Union and western Europe, the job of communicating would have been far tougher and it is not clear that proper perspectives on risk would have been achieved.

The good news is that enough is known about radiation and about risk communication to enable us to craft useful risk comparisons, if we devote proper attention and resources to doing so (see, e.g., the effort by Johnson, Fisher, Smith, \& Desvousges ${ }^{(58)}$ to inform homeowners about their risks from radon; and the recommendations by Adelstein ${ }^{(59)}$ ).

\section{Mental Models}

An important new development is the use of mental models to guide risk-communication efforts. ${ }^{(60-61)}$ Mental models are detailed representations of a person's knowledge and beliefs about a hazard and its consequences. These models are elicited by means of an interview procedure, beginning with open-ended questions (e.g., "what do you know about radon?") and proceeding to more specific questions about exposure, effects, and mitigation issues. Ultimately, the person's valid knowledge and misconceptions are identified and risk communication is 
Perception of Risk From Radiation / 22

designed to fill knowledge gaps and correct misconceptions. This technique has been applied, with some success, in the design of brochures to inform people about the risks of radon (Atman et al., 1994; Bostrom et al., 1994).

\section{Framing Effects}

It would be comforting to believe that risk attitudes and perceptions, if erroneous, would respond to informational and educational programs. Unfortunately, psychological research demonstrates that people's beliefs change slowly and are extraordinarily persistent in the face of contrary evidence. ${ }^{(62)}$ Once formed, initial impressions tend to structure the way that subsequent evidence is interpreted. New evidence appears reliable and informative if it is consistent with one's initial beliefs; contrary evidence is dismissed as unreliable, erroneous, or unrepresentative.

When people lack strong prior opinions, the opposite situation exists-they are at the mercy of the way that the information is presented. Subtle changes in the way that risks are "framed" or expressed can have a major impact on perceptions and decisions. One dramatic example of framing in the context of medical decision making comes from a study by McNeil, Pauker, Sox, and Tversky ${ }^{(63)}$ who asked people to imagine that they had lung cancer and had to choose between surgery or radiation therapy. The two treatments were described in some detail. Then, some subjects were presented with the cumulative probabilities of surviving for varying lengths of time after the treatment. Other subjects received the same cumulative probabilities framed in terms of dying rather than surviving (e.g., instead of being told that $68 \%$ of those having surgery will have survived after one year, they were told that $32 \%$ will have died-see Table 4). Framing the statistics in terms of dying dropped the percentage of subjects choosing radiation therapy over surgery from $44 \%$ to $18 \%$. The effect was as strong for physicians as for laypersons. 
Perception of Risk From Radiation / 23

Insert Table 4 about here

Numerous other examples of "framing effects" have been demonstrated by Tversky and Kahneman ${ }^{(64)}$ and others. The fact that subtle differences in how risks are presented can have such marked effects suggests that those responsible for information programs have considerable ability to manipulate perceptions and behavior. This possibility raises ethical problems that must be addressed by any responsible risk-information program.

\section{$\underline{\text { Risk Communication and Trust }}$}

Social relationships of all types, including risk management, rely heavily on trust. Indeed, much of the contentiousness that has been observed in the risk-management arena has been attributed to a climate of distrust that exists between the public, industry, and risk-management professionals. ${ }^{(65-66)}$

Also, as noted earlier, greater public acceptance of medical technologies based on chemicals and radiation, as opposed to industrial technologies, can be explained by the relatively high degree of trust in physicians and other health-care workers. Typical of the research findings are the conclusions of Bord and $\mathrm{O}^{\prime}$ Connor ${ }^{(25)}$ regarding their survey of public acceptance of food irradiation: "The most consistent, dramatic finding ... is the impact of trust on acceptability: trust in industry in general, in the food irradiation industry specifically, in government regulatory agencies, and in science itself' (p. 505).

The limited effectiveness of risk-communication efforts in many circumstances can be attributed to the lack of trust. If you trust the risk manager, communication is relatively easy. If 
trust is lacking, no form or process of communication will be satisfactory. ${ }^{(54,67)}$ Thus trust is more fundamental to conflict resolution than is risk communication.

One of the most fundamental qualities of trust has been known for ages. Trust is fragile. It is typically created rather slowly, but it can be destroyed in an instant-by a single mishap or mistake. Thus, once trust is lost, it may take a long time to rebuild it to its former state. In some instances, lost trust may never be regained. Abraham Lincoln understood this quality. In a letter to Alexander McClure he observed: "If you once forfeit the confidence of your fellow citizens, you can never regain their respect and esteem" [italics added].

The fact that trust is easier to destroy than to create reflects certain fundamental mechanisms of human psychology called here "the asymmetry principle." When it comes to winning trust, the playing field is not level. It is tilted toward distrust, for each of the following reasons:

1. Negative (trust-destroying) events are more visible or noticeable than positive (trustbuilding) events. Negative events often take the form of specific, well-defined incidents such as accidents, lies, discoveries of errors or other mismanagement. Positive events, while sometimes visible, more often are fuzzy or indistinct. For example, how many positive events are represented by the safe operation of a nuclear power plant for one day? Is this one event? dozens of events? hundreds? There is no precise answer. When events are invisible or poorly defined, they carry little or no weight in shaping our attitudes and opinions.

2. When events do come to our attention, negative (trust-destroying) events carry much greater weight than positive events. This important psychological tendency is illustrated by a study in which 103 college students rated the impact on trust of 45 hypothetical news events 
pertaining to the management of a large nuclear power plant in their community. ${ }^{(65)}$ Some of these events were designed to be trust increasing, such as

- There have been no reported safety problems at the plant during the past year.

- There is careful selection and training of employees at the plant.

- Plant managers live nearby the plant.

- The county medical examiner reports that the health of people living near the plant is better than the average for the region.

Other events were designed to be trust decreasing, such as

- A potential safety problem was found to have been covered up by plant officials.

- Plant safety inspections are delayed in order to meet the electricity production quota for the month.

- A nuclear power plant in another state has a serious accident.

- The county medical examiner reports that the health of people living near the plant is worse than the average for the region.

The respondents were asked to indicate, for each event, whether their trust in the management of the plant would be increased or decreased on learning of that event. After doing this, they rated how strongly their trust would be affected by the event on a scale ranging from 1 (very small impact on trust) to 7 (very powerful impact on trust).

The percentages of Category 7 ratings, shown in Figure 4, dramatically demonstrate that negative events are seen as far more likely to have a powerful effect on trust than are positive events. 


\section{Insert Figure 4 about here}

There was only one event perceived to have any substantial impact on increasing trust. This event stated that:

An advisory board of local citizens and environmentalists is established to monitor the plant and is given legal authority to shut the plant down if they believe it to be unsafe.

This strong delegation of authority to the local public was rated 6 or 7 on the impact scale by $38.4 \%$ of the respondents. Although this was a far stronger showing than for any other positive event, it would have been a rather average performance in the distribution of impacts for negative events.

The importance of an event is at least in part related to its frequency (or rarity). An accident in a nuclear plant is more informative with regard to risk, than is a day (or even a large number of days) without an accident. Thus, in systems where we are concerned about low-probability/high consequence events, problematic events will increase our perceptions of risk to a much greater degree than favorable events will decrease them.

3. Adding fuel to the fire of asymmetry is yet another idiosyncracy of human psychology—sources of bad (trust-destroying) news tend to be seen as more credible than sources of good news. For example, in several studies of what they called "intuitive toxicology," Kraus et al. ${ }^{(20)}$ examined people's confidence in the ability of animal studies to predict human health effects from chemicals. In general, confidence in the validity of animal studies was not particularly high. However, when told that a study has found that a chemical is carcinogenic in animals, people expressed considerable confidence in the validity of this study for predicting 
health effects in humans. Regulators respond like the public. Positive (bad news) evidence from animal bioassays is presumptive evidence of risk to humans; negative evidence (e.g., the chemical was not found to be harmful) carries little weight. ${ }^{(68)}$

4. Another important psychological tendency is that distrust, once initiated, tends to reinforce and perpetuate distrust. This occurs in two ways. First, distrust tends to inhibit the kinds of personal contacts and experiences that are necessary to overcome distrust. By avoiding others whose motives or actions we distrust, we never get to see that these people are competent, weilmeaning, and trustworthy. Second, initial trust or distrust colors our interpretation of events, thus reinforcing our prior beliefs. Persons who trusted the nuclear power industry saw the events at Three Mile Island as demonstrating the soundness of the "defense in depth" principle, noting that the multiple safety systems shut the plant down and contained most of its radiation. Persons who distrusted nuclear power prior to the accident took an entirely different message from the same events, perceiving that those in charge did not understand what was wrong or how to fix it and that catastrophe was averted only by sheer luck.

Appreciation of those psychological tendencies that create and reinforce distrust leads us toward a new perspective on risk perception and conflict. Conflicts and controversies surrounding risk management are not due to public irrationality or ignorance but, instead, can be seen as expected side effects of these psychological tendencies, interacting with a highly participatory Democratic system of government, and amplified by certain powerful technological and social changes in society. The technological change has given the electronic and print media the capability (effectively utilized) of informing us of news from all over the world—often right as it happens. Moreover, just as individuals give greater weight and attention to negative events, 
Perception of Risk From Radiation / 28

so do the news media. Much of what the media reports is bad (trust-destroying) news. ${ }^{(69)}$ This is convincingly demonstrated by Koren and Klein, ${ }^{70}$ who compared the rates of newspaper reporting of two studies, one providing bad news and one good news, published back to back in the March 20, 1991 issue of the Journal of the American Medical Association. Both studies examined the link between radiation exposure and cancer. The bad news study showed an increased risk to leukemia in white men working at the Oak Risk National Laboratory. The good news study failed to show an increased risk of cancer in people residing near nuclear facilities. Koren and Klein found that subsequent newspaper coverage was far greater for the study showing increased risk.

The social change is the rise of powerful special interest groups-well funded (by a fearful public) and sophisticated in using their own experts and the media to communicate their concerns and their distrust to the public in order to influence risk policy debates and decisions. ${ }^{(71)}$ The social problem is compounded by the fact that we tend to manage our risks within an adversarial legal system that pits expert vs. expert, contradicting each other's risk assessments and further destroying the public trust.

The young science of risk assessment is too fragile, too indirect, to prevail in such a hostile atmosphere. Scientific analysis of risks cannot allay our fears of low-probability catastrophes or delayed cancers unless we trust the system. In the absence of trust, science (and risk assessment) can only feed distrust, by uncovering more bad news. A single study demonstrating an association between exposure to chemicals or radiation and some adverse health effect cannot easily be offset by numerous studies failing to find such an association. Thus, for example, the more studies that are conducted looking for effects of electric and magnetic fields or other 
difficult to evaluate hazards, the more likely it is that these studies will increase public concerns, even if the majority of these studies fail to find any association with ill health. ${ }^{(26-27)}$ In short, risk-assessment studies may tend to increase perceived risk.

\section{Implications for Radiation Medicine}

In 20 years of research on perception and acceptance of technological risks, there has been remarkably little attention given to the medical uses of radiation—quite a contrast to the hundred or more studies of perceptions of nuclear power and nuclear waste. This lack of attention is surprising, given the importance of radiation medicine and the fact that some procedures such as mammography screening for younger women have been the source of much concern and controversy.

In the absence of studies specifically directed to radiation medicine, one can only speculate about public views, based on more general findings. The use of radiation for diagnosis and therapy will likely stand apart from other radiation technologies because people see great benefits from medical radiation and they have relatively high trust in the medical profession. Where the need is particularly evident (e.g., cancer therapy), tolerance of risk will be quite high, as shown by the strong desire of AIDS patients to have access to new, potentially dangerous medicines. ${ }^{(72)}$ But acceptance of radiation exposures will undoubtedly come with anxieties, due to the association of such exposures with the cause of cancer as well as the cure. Moreover, the public will likely support strict controls over radiation medicine regardless of costs and they will react strongly to incidents of improper or incompetent administration. Research on the "social amplification of risk" shows that even "small incidents" can produce massive "ripple effects" if they are perceived to be caused by managerial incompetence or other blameworthy factors. ${ }^{(73)}$ 
Perception of Risk From Radiation / 30

Such ripple effects could include loss of public confidence, reluctance of patients to undergo necessary examinations and treatments, extensive litigation against physicians, hospitals, and manufacturers, and demand for stricter regulatory control.

Ultimately, the best way to understand the public's view of radiation medicine is to ask people directly-by means of one-on-one interviews, focus groups, and structured surveys. In this way we can obtain a "clear image" of people's mental models pertaining to various diagnostic and therapeutic procedures, including their knowledge and misconceptions, their perceptions of risk and benefit, and their attitudes toward the use and regulation of these procedures.

Such data are really quite easy to collect. The methods are developed and the costs are reasonable. In the past, focused surveys have rarely failed to provide insights that are useful for education and policy. 
Perception of Risk From Radiation / 31

\section{References}

1. Slovic, P. Perception of Risk, Science 236 280-285 (1987).

2. Fischhoff, B., Slovic, P., Lichtenstein, S., Read, S., and Combs, B. How Safe is Safe Enough? A Psychometric Study of Attitudes Towards Technological Risks and Benefits, Pol. Sci. 9 127-152 (1978).

3. Slovic, P., Fischhoff, B., and Lichtenstein, S. Rating the Risks, Environment 21(3) 14-20, 36-39 (1979).

4. Slovic, P., Fischhoff, B., and Lichtenstein, S., Facts and Fears: Understanding Perceived Risk, in Schwing, R. and Alberts, W. A. Jr. Societal Risk Assessment: How Safe is Safe Enough? pp. 181-214, Plenum (New York, 1980a).

5. Kunreuther, H., Desvousges, W. H., and Slovic, P., Nevada's Predicament: Public Perceptions of Risk from the Proposed Nuclear Waste Repository, Environment 30(8) 16-20, 3033 (1988).

6. Slovic, P., Kraus, N. N., Lappe, H., Letzel, H., and Malmfors, T. Risk Perception of Prescription Drugs: Report on a Survey in Sweden, Pharm. Med. 4 43-65 (1989).

7. Slovic, P., Kraus, N. N., Lappe, H., and Major, M. Risk Perception of Prescription Drugs: Report on a Survey in Canada, Canadian J. of Public Health 82 S15-S20 (1991).

8. Englander, T., Farago, K., Slovic, P., and B. Fischhoff, "A Comparative Analysis of Risk Perception in Hungary and the United States," Social Behaviour: An International J. of Applied Social Psychology 1, 55-66 (1986).

9. Teigen, K. H., Brun, W., and Slovic, P. Societal Risks as Seen by a Norwegian Public, J. of Behav. Decision Making 1 111-130 (1988). 
Perception of Risk From Radiation / 32

10. Flynn, J. H., Slovic, P., C. K. Mertz, and J. Toma, Evaluations of Yucca Mountain.

Technical Report (Carson City, NV, Nuclear Waste Project Office, 1990).

11. Sjöberg, L. and Drottz-Sjöberg, B., Risk Perception, in Swedish Risk Academy Radiation and Society: Comprehending Radiation Risk vol. 1, pp. 29-60, International Atomic Energy Agency, (Vienna, 1994a).

12. Sjöberg, L. and Drottz-Sjöberg, B., Risk Perception of Nuclear Waste: Experts and the Public. Rhizikon Risk Research Report No. 16 (Stockholm, Stockholm School of Economics, Center for Risk Research, 1994b).

13. Slovic, P., Layman, M., Kraus, N. N., Flynn, J. H., Chalmers, J., and Gesell, B. Perceived Risk, Stigma, and Potential Economic Impacts of a High-level Nuclear Waste Repository in Nevada, Risk Anal. 11 683-696 (1991).

14. Slovic, P., Layman, M., and Flynn, J. H. Images of a Place and Vacation Preferences: Report of the 1989 Surveys. Nevada Nuclear Waste Project Office (Carson City, NV). Report No. NWPO-SE-030-90 (1990).

15. Slovic, P., Lichtenstein, S., and Fischhoff, B., Images of Disaster: Perception and Acceptance of Risks from Nuclear Power, in Goodman, G. and Rowe, W. Energy Risk Assessment, pp. 223-245 Academic (London, 1979).

16. Weart, S. Nuclear Fear: A History of Images Harvard (Cambridge, MA, 1988).

17. Smith, K. Perception of Risks Associated with Nuclear Power, Energy Env. Monitor 4(1) $61-70(1988)$.

18. Erikson, K. Toxic Reckoning: Business Faces a New Kind of Fear, Harvard Bus. Rev. 118-126 (January-February, 1990). 
Perception of Risk From Radiation / 33

19. Erikson, K. Radiation's Lingering Dread, The Bull. of the Atomic Scientists 34-39

(March, 1991).

20. Kraus, N. N., Malmfors, T., and Slovic, P., Intuitive Toxicology: Expert and Lay Judgments of Chemical Risks, Risk Anal. 12 215-232 (1992).

21. Slovic, P., Flynn, J. H., Mertz, C. K., and Mullican, L. Health Risk Perception in Canada. Department of National Health and Welfare (Ottawa) Report No. 93-EHD-170 (1993).

22. Tengs, T. D., Adams, M. E., Pliskin, J. S., Safran, D. G., Siegel, J. E., Weinstein, M. $\bar{C}$., and Graham, J. D. Five-hundred Life-saving Interventions and Their Cost Effectiveness Harvard School of Public Health, Center for Risk Analysis (1993).

23. Sandman, P. M., Weinstein, N. D., and Klotz, M. L. Public Response to the Risk from Geological Radon, J. of Comm. 37 93-108 (1987).

24. Carlson, E. Suburban Radium Lode Gives New Jersey a Headache, Wall Street J. 23 (December 23, 1986).

25. Bord, R. J. and O'Connor, R. E. Risk Communication, Knowledge, and Attitudes: Explaining Reactions to a Technology Perceived as Risky, Risk Anal. 20 499-506 (1990).

26. Morgan, M. G., Slovic, P., Nair, I., Geisler, D., MacGregor, D., Fischhoff, B., Lincoln, D., and Florig, K. Powerline Frequency Electric and Magnetic Fields: A Pilot Study of Risk Perception, Risk Anal. 5 139-149 (1985).

27. MacGregor, D., Slovic, P., and Morgan, M. G., "Perception of Risks from Electromagnetic Fields: A Psychometric Evaluation of a Risk-communication Approach," Risk Anal. 14 (5), 815-828 (1994).

28. Florig, H. K. Containing the Costs of the EMF Program, Science 257 468-492 (1992). 
Perception of Risk From Radiation / 34

29. Drottz-Sjoberg, B. and Persson, L. Public Reaction to Radiation: Fear, Anxiety or Phobia? Health Phys. 64 223-231 (1993).

30. United States Environmental Protection Agency Unfinished Business: A Comparative Assessment of Environmental Problems Author (Washington, DC, 1987).

31. Evans, N. and Hope, C. Nuclear Power: Futures, Costs, and Benefits Cambridge University (Cambridge, UK, 1984).

32. Heising, C. D., and George, V. P. Nuclear Financial Risk: Economy-wide Costs of Reactor Accidents, Energy Pol. 14 45-52 (1986).

33. Kasperson, R., Renn, O., Slovic, P., Brown, H., Emel, J., Goble, R., Kasperson, J., and Ratick, S., The Social Amplification of Risk: A Conceptual Framework, Risk Anal. 8 177-187 (1988).

34. Petterson, J. S. Perception Vs. Reality of Radiological Impact: The Goiania Model, Nuclear News 31(14) 84-90 (1988).

35. Covello, V. T., Sandman, P. M., and Slovic, P. Risk Communication, Risk Statistics, and Risk Comparisons: A Manual for Plant Managers Chemical Manufacturers Association (Washington, DC, 1988):

36. Covello, V. T., von Winterfeldt, D., and Slovic, P. Risk Communication: Research and Practice. Unpublished manuscript, Columbia University, School of Public Health (New York, 1988).

37. Covello, V. T., von Winterfeldt, D., and Slovic, P. Risk Communication: A Review of the Literature, Risk Abs. 3 171-182 (1986). 
Perception of Risk From Radiation / 35

38. Hance, B. J., Chess, C., and Sandman, P. M. Improving Dialogue with Communities: A Risk Communication Manual for Government New Jersey Department of Environmental Protection (Trenton, NJ, 1988).

39. Krimsky, S. and Plough, A., Environmental Hazards: Communicating Risks as a Social Provess Auburn House (Dover, MA, 1988).

40. Sandman, P. M. Explaining Environmental Risk. Environmental Protection Agency, Office of Toxic Substances (Washington, DC) Report No. TS-799 (1986).

41. Slovic, P. Informing the Public About the Risks from Ionizing Radiation, Health Phys. 41 589-598 (1981).

42. Slovic, P. Informing and Education the Public About Risk, Risk Anal. 4 403-415 (1986).

43. Slovic, P., Fischhoff, B., and Lichtenstein, S., Informing People About Risk, Report No. 6 in Morris, L., Mazis, M., and Barofsky, I. Product Labeling and Health Risks, pp. 165-181 The Banbury Center (Cold Spring Harbor, NJ, 1980b).

44. Sharlin, H. I. EDB: A Case Study in the Communication of Health Risk, Risk Anal. 6 61$68(1986)$

45. Sowby, F. D. Radiation and Other Risks, Health Phys. 11 879-887 (1965).

46. Rothschild, N. Coming to Grips with Risk, Address Presented on BBC Television; Reprinted in the Wall Street Journal (November, 1978).

47. Wilson, R. Analyzing the Daily Risks of Life, Tech. Rev. 81 40-46 (1979).

48. Cohen, B. and Lee, I. A Catalog of Risks, Health Phys. 36 707-722 (1979).

49. Reissland, J. and Harries, V. A Scale for Measuring Risks, New Sci. 83 809-811 (1979). 
Perception of Risk From Radiation / 36

50. Huyskens, C. Problems in Risk Comparisons, in Swedish Risk Academy Radiation and Society: Comprehending Radiation Risk vol. 1, pp. 131-146, International Atomic Energy Agency (Vienna, 1994).

51. Slovic, P., Kraus, N: N., and Covello, V. What Should We Know About Making Risk Comparisons? Risk Anal. 10(3) 389-392 (1990).

52. Wilson, R. Testimony Before the Subcommittee on Nuclear Regulation, Committee on the Environment and Public Works U. S. Senate (Washington, DC, May 7, 1987).

53. Drottz, B. and Sjöberg, L., Risk Perception and Worries After the Chernobyl Accident, J. of Env. Psych.10 135-149 (1990).

54. Gadomska, M. Risk Communication. In Swedish Risk Academy Radiation and Society: Comprehending Radiation Risk. International Atomic Energy Agency vol. 1, pp. 147-166 (Vienna, 1994).

55. Hohenemser, C. and Renn, O., Chernobyl's Other Legacy: Shifting Public Perceptions of Nuclear Risk, Environment 303 (1988).

56. Otway, H., Haastrup, P., Connell, W., Gianitsopoulas, G., and Paruccini, M. Risk Communication in Europe After Chernobyl: A Media Analysis of Seven Countries, Ind. Crisis Quarterly 231-35 (1988).

57. Wynne, B. Sheepfarming After Chernobyl: A Case Study in Communicating Scientific Information, Environment 31(2) 10-15; 33-39 (March, 1989).

58. Johnson, F. R., Fisher, A., Smith, V. K., and Desvousges, W. H., Informed Choice or Regulated Risk? Lessons from a Stidy in Radon Communication, Environment 30(4) 12-15; 30$35(1988)$. 
Perception of Risk From Radiation / 37

59. Adelstein, S. J. Uncertainty and Relative Risks of Radiation Exposure, J. of the American Medical Association 258 655-657 (1987).

60. Atman, C. J., Bostrom, A., Fischhoff, B., and Morgan, M. G. Designing Risk

Communications: Completing and Correcting Mental Models of Hazards Processes, Part I, Risk Anal. 14(5) 779-788 (1994).

61. Bostrom, A., Atman, C. J., Fischhoff, B., and Morgan, M. G. Evaluating Risk Communications: Completing and Correcting Mental Models of Hazards Processes, Part II, Risk Anal. 14(5) 789-798 (1994).

62. Nisbett, R. and Ross, L. Human Inference: Strategies and Shortcomings of Social Judgment Prentice-Hall (Englewood Cliffs, NJ, 1980).

63. McNeil, B. J., Pauker, S. G., Sox, H. C. Jr., and Tversky, A., On the Elicitation of Preferences for Alternative Therapies, New Eng. J. of Med. 306 1259-1262 (1982).

64. Tversky, A. and Kahneman, D. The Framing of Decisions and the Psychology of Choice, Science 211 453-458 (1981).

65. Slovic, P. Perceived Risk, Trust, and Democracy: A Systems Perspective, Risk Anal. 13, 675-682 (1993).

66. Slovic, P., Flynn, J. H., and Layman, M., Perceived Risk, Trust, and the Politics of Nuclear Waste, Science 254 1603-1607 (1991).

67. Fessendon-Raden, J., Fitchen, J. M., and Heath, J. S. Providing Risk Information in Communities: Factors Influencing What is Heard and Accepted, Sci. Tech. and Hum. Values 12 94-101 (1987).

68. Efron, E. The Apocalyptics Simon \& Schuster (New York, 1984). 
Perception of Risk From Radiation / 38

69. Lichtenberg, J. and MacLean, D. Is Good News No News? The Geneva papers on risk and insurance 17 362-365 (1992).

70. Koren, G. and Klein, N., Bias Against Negative Studies in Newspaper Reports of Medical Research, J. of the American Medical Association 266 1824-1826 (1991).

71. Wall Street Journal How a PR Firm Executed the Alar Scare pp. A1-A3 (October 3, 1989).

72. Levi, J. Unproven AIDS Therapies: The Food and Drug Administration and DdI, in Hanna, K. E. (ed.) Bio-medical Politics National Academy, 9-37 (Washington, DC, 1991).

73. Burns, W. J., Slovic, P., Kasperson, R. E., Kasperson, J. X., Renn, O., and Emani, S. Incorporating Structural Models Into Research on the Social Amplification of Risk: Implications for Theory Construction and Decision Making, Risk Anal. 13 611-623 (1993). 
Table 1. Ordering of Perceived Risk for 30 Activities and Technologies

\begin{tabular}{|c|c|c|c|c|}
\hline & Experts & $\begin{array}{c}\text { League of } \\
\text { Women Voters }\end{array}$ & $\begin{array}{c}\text { College } \\
\text { students }\end{array}$ & $\begin{array}{c}\text { Active Club } \\
\text { members }\end{array}$ \\
\hline Nuclear power & 20 & 1 & 1 & 8 \\
\hline Motor vehicles & 1 & 2 & 5 & 3 \\
\hline Handguns & 4 & 3 & 2 & 1 \\
\hline Smoking & 2 & 4 & 3 & 4 \\
\hline Motorcycles. & 6 & 5 & 6 & 2 \\
\hline Alcoholic beverages & 3 & 6 & 7 & 5 \\
\hline General (private) aviation & 12 & 7 & 15 & 11 \\
\hline Police work & 17. & 8 & 8 & 7 \\
\hline Pesticides & 8 & 9 & 4 & 15 \\
\hline Surgery & 5 & 10 & 11 & 9 \\
\hline Fire fighting & 18 & 11 & 10 & 6 \\
\hline Large construction & 13 & 12 & 14 & 13 \\
\hline Hunting & 23 & 13 & 18 & 10 \\
\hline Spray cans & 26 & 14 & 13 & 23 \\
\hline Mountain climbing & 29 & 15 & 22 & 12 \\
\hline Bicycles & 15 & 16 & 24 & 14 \\
\hline Commercial aviation & 16 & 17 & 16 & 18 \\
\hline Electric power (non-nuclear) & 9 & 18 & 19 & 19 \\
\hline Swimming & 10 & 19 & 30 & 17 \\
\hline Contraceptives & 11 & 20 & 9 & 22 \\
\hline Skiing & 30 & 21 & 25 & 16 \\
\hline X-rays & 7 & 22 & 17 & 24 \\
\hline High school and college football & 27. & 23 & 26 & 21 \\
\hline Railroads & 19 & 24 & 23 & 20 \\
\hline Food preservatives & 14 & 25 & 12 & 28 \\
\hline Food coloring & 21 & 26 & 20 & 30 \\
\hline Power mowers & 28 & 27 & 28 & 25 \\
\hline Prescription antibiotics & 24 & 28 & 21 & 26 \\
\hline Home appliances & 22 & 29 & 27 & 27 \\
\hline Vaccinations & 25 & 30 & 29 & 29 \\
\hline
\end{tabular}

Note. The ordering is based on the geometric mean risk ratings within each group. Rank 1 represents the most risky activity or technology. 
Perception of Risk From Radiation / 40

Table 2. Hierarchy of Images Associated With an "Underground Nuclear Waste Storage Facility"

\begin{tabular}{|c|c|c|}
\hline Category & Frequency & Images included in category \\
\hline 1. Dangerous & 179 & $\begin{array}{l}\text { dangerous, danger, hazardous, } \\
\text { toxic, unsafe, harmful, disaster }\end{array}$ \\
\hline 2. Death/disease & 107 & $\begin{array}{l}\text { death, sickness, dying, } \\
\text { destruction, lethal, cancer, } \\
\text { deformities }\end{array}$ \\
\hline 3. Negative & 99 & $\begin{array}{l}\text { negative, wrong, bad, unpleasant, } \\
\text { terrible, gross, undesirable, awful, } \\
\text { dislike, ugly, horrible }\end{array}$ \\
\hline 4. Pollution & 97 & $\begin{array}{l}\text { pollution, contamination, leakage, } \\
\text { spills, Love Canal }\end{array}$ \\
\hline 5. War & 62 & $\begin{array}{l}\text { war, bombs, nuclear war, } \\
\text { holocaust }\end{array}$ \\
\hline 6. Radiation & 59 & $\begin{array}{l}\text { radiation, nuclear, radioactive, } \\
\text { glowing }\end{array}$ \\
\hline 7. Scary & 55 & $\begin{array}{l}\text { scary, frightening, concern, } \\
\text { worried, fear, horror }\end{array}$ \\
\hline 8. Somewhere Else & 49 & $\begin{array}{l}\text { wouldn't want to live near one, } \\
\text { not where I live, far away as } \\
\text { possible }\end{array}$ \\
\hline 9. Unnecessary & 44 & $\begin{array}{l}\text { unnecessary, bad idea, waste of } \\
\text { land }\end{array}$ \\
\hline 10. Problems & 39 & problems, trouble \\
\hline 11. Desert & 37 & desert, barren, desolate \\
\hline 12. Non-NV locations & 35 & Utah, Arizona, Denver \\
\hline 13. Storage location & 32 & caverns, underground salt mine \\
\hline 14. Government/industry & 23 & government, politics, big business \\
\hline
\end{tabular}

Source. Slovic et al., 1989; survey of 400 residents of Phoenix, Arizona. 
Perception of Risk From Radiation / 41

Table 3. Summary of Perception and Acceptance of Risks From Diverse Sources of Radiation Exposure

\begin{tabular}{|c|c|c|}
\hline & \multicolumn{2}{|c|}{ Perceived risk } \\
\hline & Technical experts & Public \\
\hline \multirow[t]{2}{*}{ Nuclear power/nuclear waste } & Moderate risk & Extreme risk \\
\hline & Acceptable & Unacceptable \\
\hline \multirow[t]{2}{*}{$\mathrm{X}$-rays } & Low/moderate risk & Very low risk \\
\hline & Acceptable & Acceptable \\
\hline \multirow[t]{2}{*}{ Radon } & Moderate risk & Very low risk \\
\hline & Needs action & Apathy \\
\hline \multirow[t]{2}{*}{ Nuclear weapons } & Moderate to extreme risk & Extreme risk \\
\hline & Tolerance & Tolerance \\
\hline \multirow[t]{2}{*}{ Food irradiation } & Low risk & Moderate to high risk \\
\hline & Acceptable & Acceptability questioned \\
\hline \multirow[t]{2}{*}{ Electric and magnetic fields } & Low risk & $\begin{array}{l}\text { Significant concerns } \\
\text { beginning to develop }\end{array}$ \\
\hline & Acceptable & Acceptability questioned \\
\hline
\end{tabular}


Perception of Risk From Radiation / 42

Table 4. A Framing Effect: Surgery vs. Radiation Therapy.

\begin{tabular}{|c|c|c|c|c|}
\hline & \multicolumn{2}{|c|}{ Mortality rates } & \multicolumn{2}{|c|}{ Survival rates } \\
\hline & Surgery & Radiation & Surgery & Radiation \\
\hline Treatment & $10 \%$ & $0 \%$ & $90 \%$ & $100 \%$ \\
\hline 1 year & 32 & 23 & 68 & 77 \\
\hline$\bullet$ & & & & \\
\hline 5 years & 66 & 78 & 34 & 22 \\
\hline $\begin{array}{l}\text { Percent choice of } \\
\text { radiation therapy }\end{array}$ & & $44 \%$ & & $18 \%$ \\
\hline
\end{tabular}

Source. McNeil et al. (1982). 
Perception of Risk From Radiation / 43

Figure Captions

Figure 1. Profiles for nuclear power and X-rays across nine risk characteristics. Source: Slovic, Fischhoff, \& Lichtenstein, 1979.

Figure 2. Location of 31 hazards on factors 1 and 2 derived from the interrelationships among 15 risk characteristics. Each factor is made up of a combination of characteristics, as indicated by the lower diagram. Source: redrawn from Slovic (1987).

Figure 3. Mean perceived risk and perceived benefit for medical and nonmedical sources of exposure to radiation and chemicals. Each item was rated on a scale of perceived risk ranging from 1 (very low risk) to 7 (very high risk) and a scale of perceived benefit ranging from 1 (very low benefit) to 7 (very high benefit). Note that medical sources of exposure have more favorable benefit/risk ratings than do the nonmedical sources. Data are from a national survey in Canada by Slovic et al. (1991).

Figure 4. Differential impact of trust-increasing and trust-decreasing events. Each event was rated on a scale ranging from 1 (very little impact on trust) to 7 (very powerful impact on trust). Only the percentage of respondents giving Category 7 ratings (very powerful impact) are shown here. Source: Slovic (1993). 

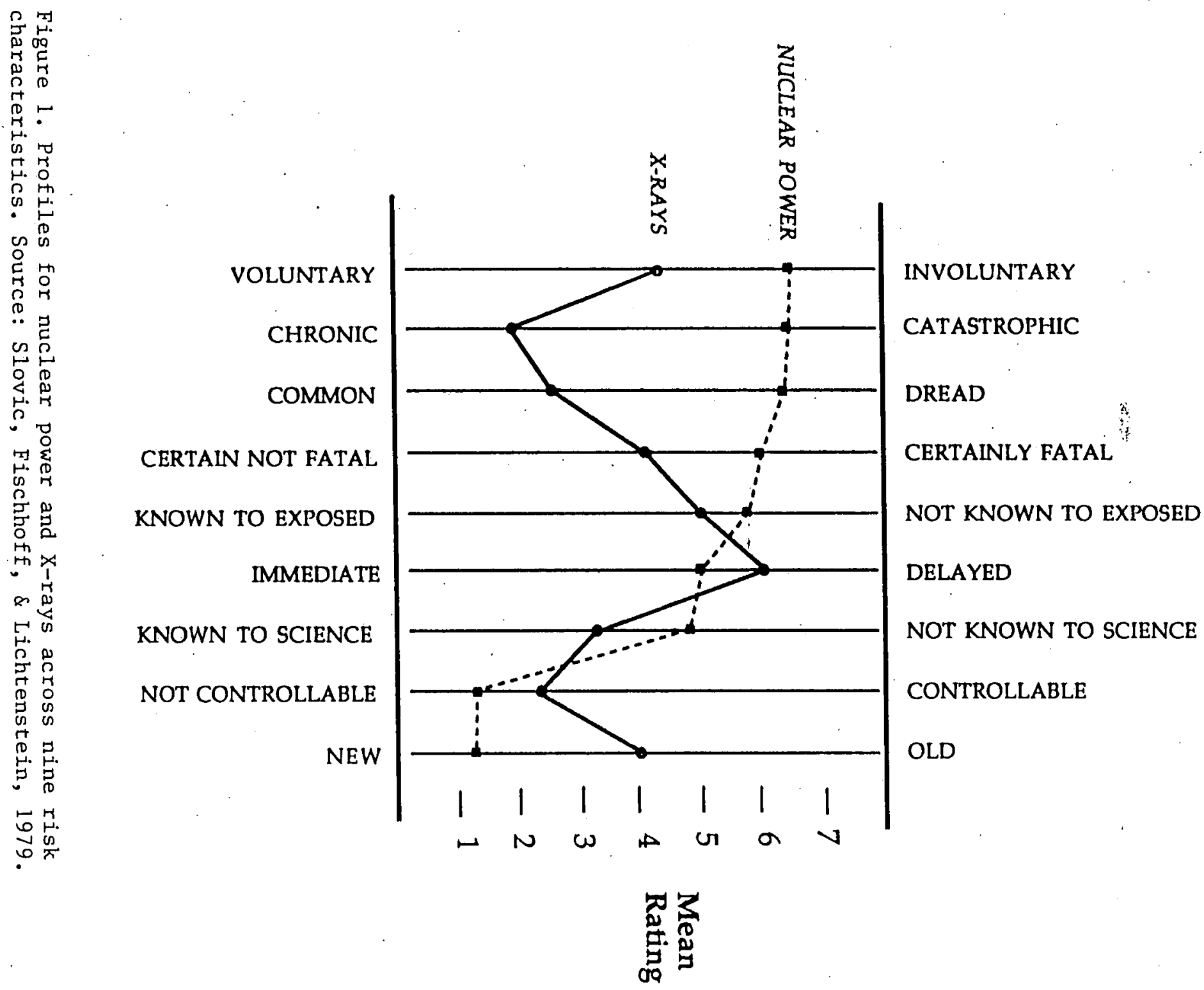


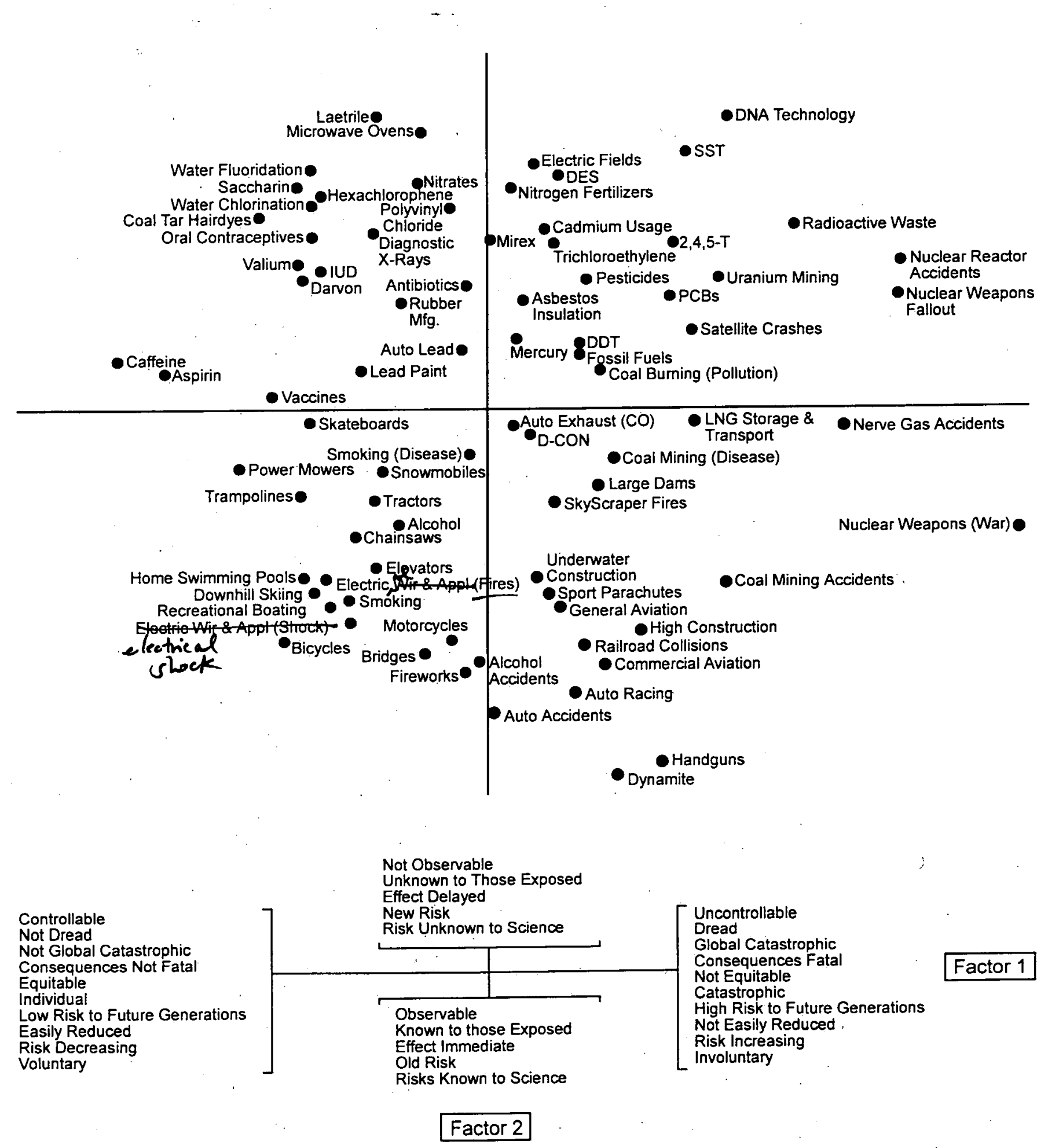

Figure 2. Location of 81 hazards on Factors 1 and 2 derived from the interrelationships among 15 risk characteristics. Each factor is made up of a combination of characteristics, as indicated by the lower diagram. Source: redrawn from Slovic, 1987. 


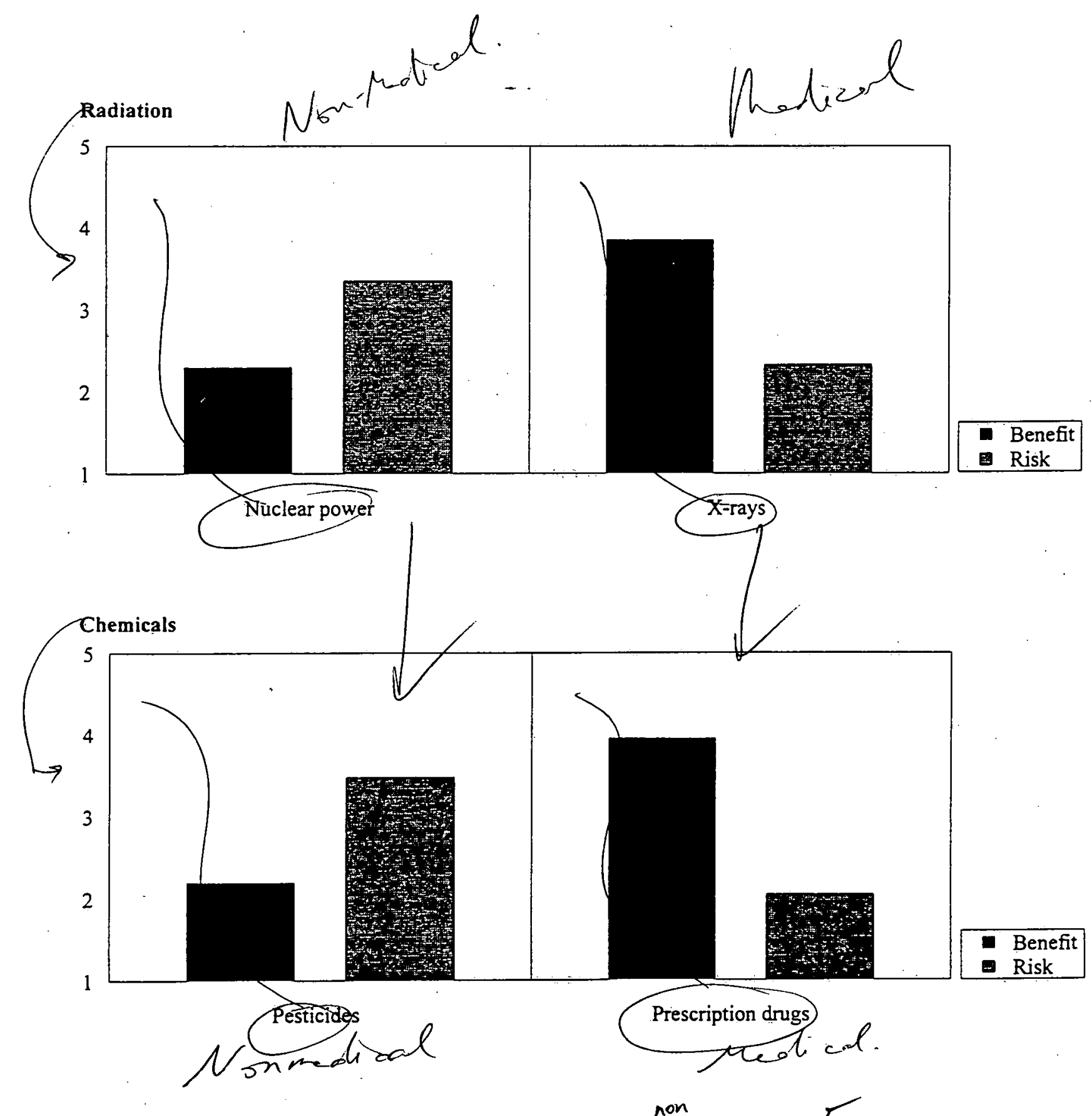

Figure 3. Mean perceived risk and perceived benefit for medical and nonmedical sources of exposure to radiation and chemicals. Each item was rated on scale $e_{1}^{s^{*}}$ perceived risk ranging 7

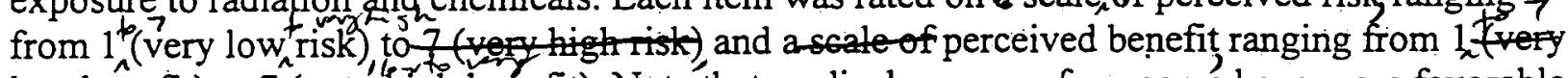
low henefit) to $\mathcal{Z}$ (very high benefit). Note that medical sources of exposure have more favorable benefit/risk ratings, than da the nonmedicalsoes. Data are from a national survey in Canada by Slovic et al., 1991.

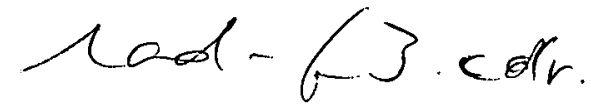




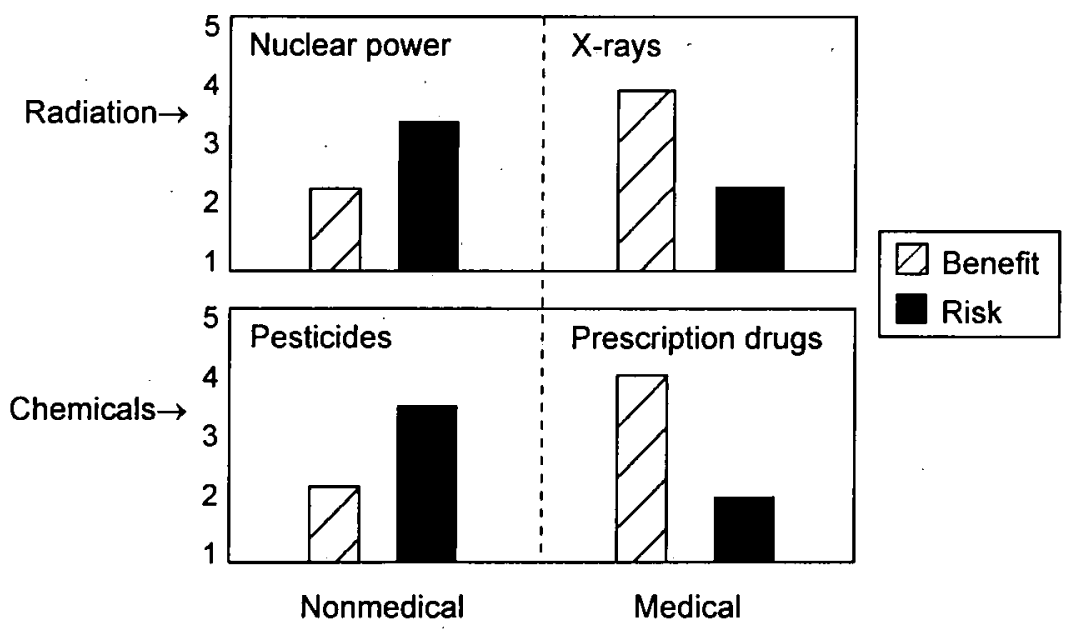

Figure 3. Mean perceived risk and perceived benefit for nonmedical and medical sources of exposure to radiation and chemicals. Each item was rated on 2 scales: perceived risk. ranging from 1 to 7 (very low to very high risk) and perceived benefit, ranging from 1 to 7 (very low to very high benefit). Note that medical sources of exposure have more favorable benefit/risk ratings. Data are from a national survey in Canada by Slovic et al., 1991. 